\title{
Porfirria cutánea tarda en un paciente VIH. ¿Papel secundario o protagonista del virus?
}

\author{
Torres León JM. ${ }^{1 a}$, Menéndez Martínez Mª A.2a, Domínguez Alegría AR. ${ }^{2 a}$, \\ Torrejón Martínez $\mathrm{M}^{\mathrm{a}} \mathrm{J}^{\mathrm{jb}}$, Espigares Correa A. ${ }^{2 \mathrm{a}}$
}

Sanid. mil. 2015; 71 (1): 29-31; ISSN: 1887-8571

\begin{abstract}
RESUMEN
La sospecha sobre la asociación de la infección por virus de la inmunodeficiencia humana (VIH), con el tipo I o forma esporádica de la porfiria cutánea tarda (PCT), comenzó pocos años después del descubrimiento del virus. La patogenia de la PCT en estos enfermos no está aclarada y, aunque en la mayoría de los pacientes se identifica más de un factor predisponenente, se considera que el propio VIH es un elemento independiente de riesgo para padecer la enfermedad. En esta comunicación se describe el caso de un paciente con infección por el VIH en el que se estableció de forma simultanea el diagnóstico de PCT.
\end{abstract}

PALABRAS CLAVE: Porfiria cutánea tarda. VIH.

Porphyria cutanea tarda in an HIV-infected patient. Secondary role or protagonist of the virus?

SUMMARY: A suspicion about the association of human immunodeficiency virus (HIV) infection with type I or sporadic form of porphyria cutanea tarda (PCT) began a few years after the discovery of the virus. The pathogenesis of PCT in these patients is unclear and although majority of the patients have more than one underlying factor for the disease, it is considered that HIV itself is an independent risk element for its development. This communication describes the case of a patient with HIV infection in whom the diagnosis of PCT was established simultaneously.

KEYWORDS: Porphyria cutanea tarda. HIV

\section{INTRODUCCIÓN}

La PCT es la más común de todas las porfirias, un grupo de trastornos del metabolismo caracterizados por un déficit enzimático específico en la biosíntesis del grupo heme y cuya consecuencia es la acumulación en el organismo de alguno de los precursores de este pigmento. En el caso de la PCT el déficit de la enzima uroporfirinógeno descarboxilasa (UROD) produce un acúmulo de porfirinas en el hígado, que transportadas hasta la piel y activadas por acción de la luz ultravioleta son las responsables de las lesiones cutáneas típicas de la enfermedad.

En las porfirias el déficit enzimático es hereditario, a excepción de la forma más frecuente de PCT, el denominado tipo I o forma esporádica de la PCT. En esta variedad se han reconocido diferentes factores relacionados con la adquisición del defecto enzimático: el consumo excesivo de alcohol, los estrógenos, la infección por virus $\mathrm{C}$ de la hepatitis o la presencia de mutaciones C282Y y H63D del gen de la hemocromatosis. El VIH se ha reconocido como un factor independiente de riesgo para su aparición, aunque por lo general no aparece aislado ${ }^{1}$. Presentamos el

${ }^{1}$ Tcol. Médico.

${ }^{2}$ Médico civil especialista.

a Servicio de Medicina Interna. Hospital Central de la Defensa Gómez Ulla. Madrid. España.

b Servicio de Análisis Clínicos. Hospital Clínico San Carlos. Madrid. España.

Dirección para correspondencia: Dr. Juan M. Torres. Servicio de Medicina Interna. Hospital Central de la Defensa «Gómez Ulla». Glorieta del Ejército 1. 28047 Madrid.

Recibido: 5 de febrero de 2014

Aceptado: 25 de marzo de 2014 caso de un paciente consumidor excesivo de alcohol en el que se establecieron los diagnósticos de infección por VIH y PCT tras ingresar en nuestro hospital.

\section{CASO APORTADO}

Un varón heterosexual de 63 años ingresó en Noviembre de 2013 por disnea progresiva de un mes de evolución que al llegar a urgencias era de mínimos esfuerzos. Era fumador, índice acumulado de 80 paquetes/año, bebedor de unos 80 gr. de alcohol al día, y tenía relaciones sexuales sin protección con diferentes parejas. No refería enfermedad hepática previa, ni tenía conocimiento de que algún miembro de su familia hubiera sido diagnosticado de porfiria. No tomaba medicación de forma habitual.

Unos meses antes había consultado con un dermatólogo por un cuadro de eritema y descamación facial que se relacionó con una fotosensibilidad excesiva, fue tratado con cremas de protección solar.

A la dificultad respiratoria se añadían otros datos: tenía tos no productiva, no refería fiebre pero a su ingreso la temperatura era de $38,5^{\circ} \mathrm{C}$ y estimaba que había perdido unos $20 \mathrm{~kg}$ de peso en los últimos 4 meses. El paciente aparentaba estar mal nutrido, se encontraba eupneico con aporte de oxígeno suplementario, el murmullo vesicular estaba conservado y no tenía signos de insuficiencia cardiaca. Se apreciaba una hiperpigmentación llamativa en la frente, regiones malares y nariz con alguna pequeña erosión e hipertricosis (Fig.1), no tenía otras lesiones cutáneas. La radiografía de tórax mostraba un patrón intersticial bilateral. Los anticuerpos anti-VIH fueron positivos, la carga viral era de 
257.580 copias/ml, las cifras de CD4 28 células/ $\mu \mathrm{L}$ y la de CD 8 262 células $/ \mu \mathrm{L}$ con un cociente CD4/CD8 de 0'11. La tinción de Ziehl Neelsen del esputo resultó negativa. No pudo obtenerse una muestra adecuada para inmunofluorescencia directa en esputo frente a pneumocystis jiroveci (PNJ), no obstante se inició tratamiento empírico frente a este hongo con el diagnóstico de presunción de neumonía intersticial por PNJ. Mejoraron la disnea y la semiología radiológica descrita. Se realizó una determinación de porfirinas fraccionadas en orina a fin de aclarar la eritrodermia facial (Tabla 1). Se detectó una elevación en la excreción de porfirinas en orina de 24 horas, con un patrón de excreción compatible con el diagnóstico de $\mathrm{PCT}^{2}$.
H63D del gen de la hemocromatosis resultaron negativas. Fue dado de alta con los diagnósticos de infección por VIH C3 (neumonía intersticial por PNJ) y PCT. Se inició tratamiento con Tenofovir, Emtricitabina y Darunavir y se recomendó protección solar y la abstinencia de alcohol.

\section{DISCUSIÓN}

En 1987 se comunicaron los primeros enfermos con sida que presentaban $\mathrm{PCT}^{3}$. La publicación de nuevos casos, en los que se comunicaba esta asociación, alentó la posibilidad de que el virus actuara como un desencadenante de este tipo de porfiria ${ }^{4,5}$. En general, es habitual que exista más de un factor de riesgo para desarrollar PCT esporádica entre los pacientes diagnosticados de esta enfermedad ${ }^{6} \mathrm{y}$ es un hecho reconocido que en los pacientes contagiados por el VIH, tanto la infección por el virus $\mathrm{C}$ de la hepatitis como el consumo excesivo de alcohol concurran con mayor frecuencia que en el resto de la población. La relación del VIH con la PCT, como un factor de riesgo independiente, cobró

fuerza con la descripción de algunos

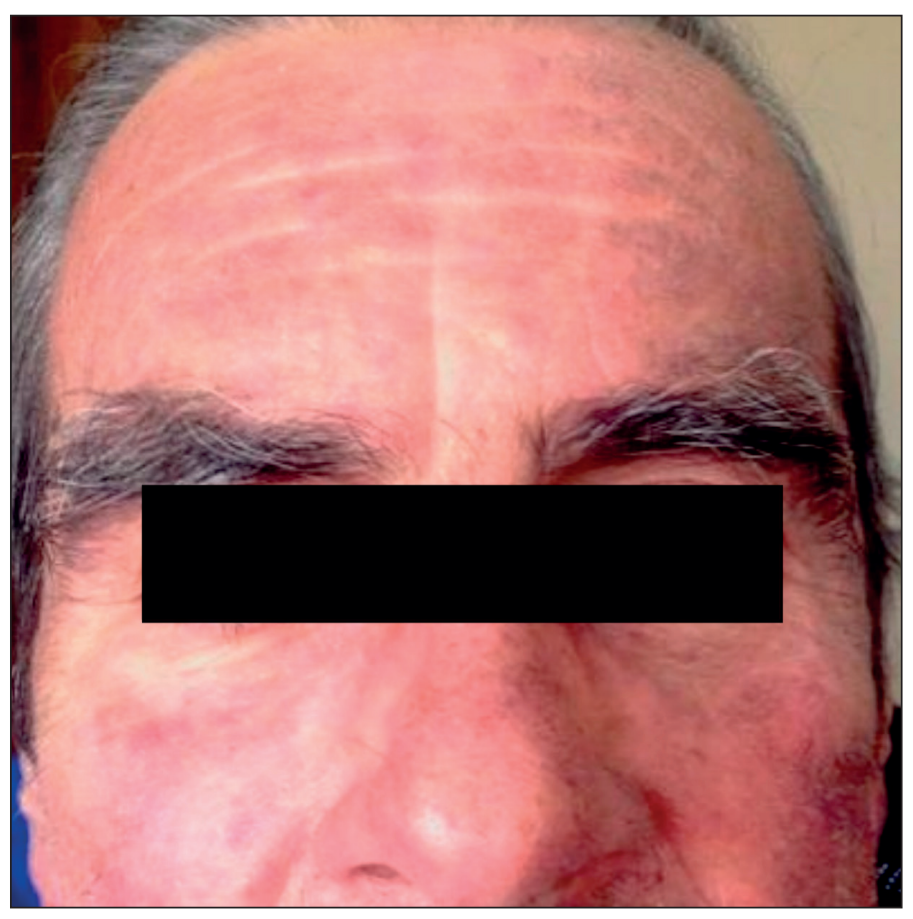

Figura 1. Hiperpigmentación ocre facial con realce de los pliegues cutáneos.

Las serologías a virus $\mathrm{B}$ y $\mathrm{C}$ de la hepatitis fueron negativas. El estudio del metabolismo del hierro mostraba unos valores normales de transferrina y ligeramente elevados de su índice de saturación y de hierro sérico, la cuantificación de ferritina sérica resultó ser muy elevada $(1.928 \mathrm{ng} / \mathrm{ml})$. Las mutaciones $\mathrm{C} 282 \mathrm{Y}$ y

\section{Valor en orina de $\mathbf{2 4} \mathrm{h}$}

$108(0-5)$

$2.1(0-2)$

$32.4(0-5)$

$72(0-25)$

$72(0-25)$

$136.8(0-75)$

$423.3(0-150)$ casos en los que no se encontraba otra predisposición que la propia infección ${ }^{7}$ o aquellos otros en los que el tratamiento antirretroviral de gran actividad (TARGA) mejoraba la porfiria aunque no se realizara un tratamiento específico contra la misma ${ }^{8}$.

La patogenia de la enfermedad está aclarada solo parcialmente. El descenso, superior al 20-25\%, de la actividad de la enzima UROD es la responsable de la acumulación de los precursores pofirínicos. En las formas heredadas (tipo 2) un defecto genético explica el déficit enzimático que afecta tanto a las células hepáticas como a los eritrocitos. En la PCT esporádica (tipo 1), el déficit de UROD afecta solo al hepatocito. En estos casos el exceso hepático de hierro, que estos pacientes presentan de forma casi constante, parece jugar un papel importante cuando se asocia con los procesos reconocidos como precipitantes de la enfermedad. Es un hecho frecuente observar siderosis en las biopsias hepáticas de estos pacientes y elevación en los valores séricos de hierro y ferritina, como en el caso que presentamos. La inactivación exclusiva de la UROD hepática podría estar mediada por un inhibidor competitivo (uoroporphomethene) resultado de la oxidación parcial de uroporfirinogeno en el citocromo P450 por un mecanismo oxidativo dependiente del hierro ${ }^{9,10}$.

Las manifestaciones clínicas de la enfermedad se delimitan a la piel expuesta al sol y son consecuencia de un exceso de fragilidad cutánea que produce la aparición de ampollas, localizadas con frecuencia en el dorso de las manos, que al romperse producen costras y pequeñas pápulas blancas llamadas milios que dejan finalmente zonas de piel atrófica y de color marrón. Es frecuente la hiperpigmentación facial y la hipertricosis. En el caso que presentamos, la afectación cutánea se limitaba a la cara, el uso previo de cremas de protección solar y la estación del año en 


\section{Porfiria cutánea tarda en un paciente VIH. ¿Papel secundario o protagonista del virus?}

la que se atendió al paciente podrían justificar la levedad de las lesiones observadas en ese momento.

El diagnóstico de la enfermedad se confirma por la elevada concentración de porfirinas en el hígado, el plasma, la orina y las heces. La PCT tipo 2 puede diferenciarse del tipo 1 por la menor concentración de UROD en los hematíes. En nuestro caso, la excreción de porfirinas en orina mostraba unos valores elevados, en especial los de uroporfirinas y los de porfirinas heptacarboxiladas.

El tratamiento de la PCT tipo 1 incluye evitar la exposición al sol y los factores desencadenantes en los casos relacionados con el alcohol o los estrógenos. Sin embargo, el efecto que sobre las manifestaciones clínicas y los niveles de porfirinas produce el tratamiento de la infección, en los casos asociados al virus $\mathrm{C}$ o el VIH, es un tema controvertido.

En el caso de la infección por virus C, existen publicaciones que informan de la mejoría de los síntomas de la PCT, de la reducción de los niveles de excreción de porfirinas en orina y del descenso de los niveles de RNA del virus C tras el tratamiento con interferon alfa ${ }^{11}$ y por el contrario otras comunican la aparición de PCT al realizarse un tratamiento combinado de interferon con ribavirina en un paciente con hepatitis $\mathrm{C}^{12}$. Un aspecto llamativo sobre la complejidad del problema, es que padecer PCT es un indicador de mala respuesta al interferon en los infectados por el virus $\mathrm{C}^{13} \mathrm{y}$, puesto que las flebotomías pueden mejorar la respuesta virológica sostenida en el tratamiento con interferon en monoterapia ${ }^{14}$, se ha propuesto la realización de flebotomías previas a la combinación del tratamiento antiviral como la pauta terapéutica más adecuado de estos pacientes ${ }^{15}$.

Los estudios sobre enfermos infectados por el VIH que padecen PCT se limitan a comunicaciones de grupos pequeños de enfermos o de casos aislados. Tal como ocurre en la infección por el virus $\mathrm{C}$, algunos autores han comunicado la mejoría de las manifestaciones de la PCT al iniciar el TARGA ${ }^{7}$ pero también hay publicaciones en las que se describen varios pacientes en los que se realiza el diagnóstico de PCT tras iniciarse este tratamiento $^{16,17}$. En los casos publicados que hemos revisado los tratamientos empleados frente a la PCT en los enfermos con VIH han variado desde las flebotomías, al uso de hidroxicloroquina o la simple protección del sol. En nuestro caso esta última opción, junto con la abstención de beber alcohol, han sido las únicas recomendaciones que se han realizado hasta valorar la evolución de las lesiones cutáneas y de los niveles de profirinas tras el inicio del TARGA.

Creemos que el caso presentado es un ejemplo más de las complejas y variadas expresiones que pueden tener las infecciones por virus tales como el de la hepatitis C o el VIH. Manifes- taciones que en ocasiones, como el caso de la PCT, pueden ser el primer indicio de la infección por el virus ${ }^{18}$.

\section{BIBLIOGRAFÍA}

1. Desnick RJ. Balwani M. Las porfirias. En Longo DL, Fauci AS, Kasper D, Hauser SL, Jameson JL, Loscalzo J (eds). Harrison Principios de Medicina Interna. $18^{a}$ edición. México: McGraw-Hill; 2012. p 3.167-3.181.

2. Hindmarsh J.T, Oliveras L, Greenway D.C. Biochemical Differentiation of the Porphyrias. Clin Biochem 1999; 32:609-619.

3. Wissel PS, Sordillo P, Anderson KE, Sassa S, Savillo RL, Kappas A. Porphyria cutanea tarda associated with the acquired immune deficiency syndrome. Am J Hematol 1987; 25: 107-11.

4. Enríquez de Salamanca R, Sanchez-Perez J, Diaz-Mora F, Garcia-Esgandon F, Pérez-Oteiza C, et al. Porphyria cutanea tarda associated with HIV infection: are those conditions pathogenetically related or merely coincidental? AIDS 1990; 4: 926-7.

5. McAlister F, McClean K, Hamilton PG, Houston S. Human immunodeficiency virus infection and porphyria cutanea tarda: coexistence of risk factors or causative association? Clin Infect Dis 1995; 20: 348-51.

6. Jalil S, Grady JJ, Lee C, Anderson KE. Associations among behavior-related susceptibility factors in porphyria cutanea tarda. Clin Gastroenterol Hepatol. 2010 Mar; 8(3):297-302.

7. Conlan MG, Hoots WK. Porphyria cutanea tarda in association with human immunodeficiency virus infection in a hemophiliac. J Am Acad Dermatol 1992; 26: 857-59.

8. Rich JD, Mylonakis E, Nossa R, Chapnick RM. Highly active antiretroviral therapy leading to resolution of porphyria cutanea tarda in a patient with AIDS and hepatitis C. Dig Dis Sci. 1999 May; 44(5):1034-7.

9. Puy H, Gouya L, Deybach JC. Porphyrias. Lancet 2010; 375: 924-37.

10. Phillips JD, Bergonia HA, Reilly CA, et al. A porphomethene inhibitor of uroporphyrinogen decarboxylase causes porphyria cutanea tarda. Proc Natl Acad Sci USA 2007; 104:5079-5084.

11. Okano J, Horie Y, Kawasaki H, Kondo M. Interferon treatment of porphyria cutanea tarda associated with chronic hepatitis type C. Hepatogastroenterology. 1997 Mar-Apr; 44(14):525-8.

12. Azim J, McCurdy H, Moseley RH. Porphyria cutanea tarda as a complication of therapy for chronic hepatitis C. World J Gastroenterol 2008; 14: 5913-5.

13. Fernandez I, Castellano G, De Salamanca RE, et al. Porphyria cutanea tarda as a predictor of poor response to interferon alfa therapy in chronic hepatitis C. Scand J Gastroenterol 2003; 38: 314-9.

14. Desai TK, Jamil LH, Balasubramaniam M, Koff R, Bonkovsky HL. Phlebotomy improves therapeutic response to interferon in patients with chronic hepatitis C: a metaanalysis of six prospective randomized controlled trials. Dig Dis Sci 2008; 53: 815-22.

15. Ryan Caballes F, Sendi H, Bonkovsky HL. Hepatitis C, porphyria cutanea tarda and liver iron: an update. Liver Int. 2012 Jul;32(6):880-93.

16. Bernardes Filho F, Santos MV, Carvalho FN, Castro CG, Dobao E, Lyra MR, Menezes Vd, Nery JA. HAART: a risk factor for development of porphyria cutanea tarda? Rev Soc Bras Med Trop. 2012 Dec;45(6):764-7.

17. Pandie M, Sonderup M, Meissner P, Mendelson M. Acute porphyria precipitated by nevirapine. AIDS. 2010 Oct 23;24(16):2597-9.

18. Ash S, Woodley DT, Chan LS. Porphyria cutanea tarda preceding AIDS. Lancet. 1996 Jan 20;347(8995):190. 